\title{
Degradação fotocalítica de bentazona com $\mathrm{TiO}_{2}$
}

\author{
Photocatalytical degradation of bentazone with $\mathrm{TiO}_{2}$ \\ Mariane Viteck Schneider', Mauricio Ferreira Rosa², Viviane da Silva Lobo ${ }^{3}$, \\ Reinaldo Aparecido Bariccatti ${ }^{4}$
}

\begin{abstract}
RESUMO
Este estudo avaliou a degradação oxidativa do herbicida pós-emergente Basagran 600 por fotólise e fotocatálise, usando $\mathrm{TiO}_{2}$ como catalisador, comparando-se a eficiência de ambos os processos. Os experimentos foram realizados irradiando-se soluções aquosas do herbicida em um reator do tipo s/urry. Os tratamentos foram acompanhados por espectrofotometria de absorção na região do UV-visível observando-se a banda centrada em $335 \mathrm{~nm}$. O primeiro processo mostrou-se pouco efetivo, sendo observada mínima redução dos valores de absorvância. Já o segundo foi muito mais eficiente, sendo observado, após 270 min de irradiação, 100\% de redução da absorvância da banda no comprimento de onda estudado. Este processo seguiu uma cinética de pseudo-primeira ordem e teve constante de velocidade (k) estimada de 0,0116 min $^{-1}$
\end{abstract}

Palavras-chave: Basagran ${ }^{\oplus}$; processo oxidativo avançado; cinética.

\begin{abstract}
This study evaluated the oxidative degradation of the post-emerging herbicide Basagran 600 by photolysis and photocatalysis using $\mathrm{TiO}_{2}$ as catalyst, and both processes were compared in their efficiency. The experiments were done irradiating aqueous solutions of the herbicide in a slurry type reactor. The treatments were accompanied by spectrophotometry in the UV-visible range observing the band centered in $335 \mathrm{~nm}$. The first process showed rather ineffective, being observed minimal reduction of the absorbance values. On the other hand, the second process was much more efficient, being observed, after 270 min of irradiation, 100\% absorbance reduction of the band in the choose wavelength. This process followed pseudo-first-order kinetic and the estimated rate constant $(k)$ was 0.0116 min $^{-1}$.
\end{abstract}

Keywords: Basagran ${ }^{\oplus}$; advanced oxidation processes; kinetics.

\section{INTRODUÇÃO}

Atualmente, uma preocupação constante é o desafio do crescimento populacional e a produção de alimento suficiente para atender esta demanda. Projeta-se para o ano 2050 uma população mundial de 9,3 bilhões de habitantes (PORTAL TERRA, 2011; BRUXELAS, 2011), o que gera uma enorme pressão pelo aumento da produtividade nos campos.

De acordo com o Instituto Brasileiro de Geografia e Estatística (IBGE), para a safra 2013 estima-se que a produção nacional atinja 181,3 milhões de toneladas, uma produção $12 \%$ superior àquela obtida em 2012 (BRASIL, 2013). Neste contexto, o estado do Paraná aparece como o segundo produtor nacional, com participação de $20,6 \%$ do total (BRASIL, 2013).
Segundo dados da Associação Brasileira de Saúde Coletiva (ABRASCO, 2012), em 2011, o Brasil gastou US\$ 8,5 bilhões na compra de defensivos agrícolas, e, destes, os herbicidas representaram cerca de $45 \%$ do total dos defensivos agrícolas comercializados.

O Basagran (BS), um defensivo agrícola produzido pela BASF, é um herbicida pós-emergente seletivo com uso recomendado para as culturas de soja, milho, feijão, arroz e trigo. O princípio ativo deste herbicida é a bentazona (3-isopropil-1H-2,1,3-benzotiadiazina-4(3H)-one-2,2-dióxido - CAS 25057-89-0) e é comercializado na forma de um concentrado solúvel com concentração de 600 g.L.-1 . Quimicamente a bentazona pertence à classe das benzotiadiazinonas apresentando a fórmula molecular $\mathrm{C}_{10} \mathrm{H}_{12} \mathrm{~N}_{2} \mathrm{O}_{3} \mathrm{~S}$ e a fórmula estrutural apresentada na Figura 1.

$\square$

'Licenciada em Química pela UNIOESTE. Pós-graduada (lato sensu) em Gerenciamento de Laboratórios pela UNIOESTE - Toledo (PR), Brasil.

²Bacharel em Química pelo Instituto de Química da Universidade Federal do Rio de Janeiro (IQ-UFRJ). Licenciado em Química pelo Instituto de Química da Universidade do Estado do Rio de Janeiro (IQ-UERJ). Mestre e Doutor em Ciências na área de concentração de Química Orgânica pelo IQ-UFRJ. Professor associado B do Centro de Engenharias e Ciências Exatas da Universidade Estadual do Oeste do Paraná (CECE-UNIOESTE). Líder do Grupo Interdisciplinar de Pesquisa em Eletroquímica e Fotoquímica Ambiental (GIPeFEA) - Toledo (PR), Brasil.

${ }^{3}$ Engenheira Química pelo (IQ-UERJ). Licenciada em Química pelo (IQ-UERJ). Mestre em Ciências na área de concentração de Química Orgânica pelo (IQ-UFRJ) e Doutora em Ciências na área de concentração de Química Inorgânica pelo IQ-UFRJ. Professora adjunta do curso de Tecnologia em Processos Químicos da Universidade Tecnológica Federal do Paraná (UTFPR). Membro do GIPeFEA - Toledo (PR), Brasil.

^Bacharel em Química com Atribuições Tecnológicas pelo Instituto de Química da Universidade Estadual de Campinas (IQ-UNICAMP). Mestre e Doutor em Físico-Química pelo IQ-UNICAMP. Professor associado C do CECE-UNIOESTE. Membro do GIPeFEA - Toledo (PR), Brasil.

Endereço para correspondência: Mauricio Ferreira Rosa - Rua da Faculdade, 645 - 85903-000 - Toledo (PR), Brasil - E-mail: mauricio_rosa@ymail.com

Recebido: 13/09/12 - Aceito: 27/09/13 - Reg. ABES: 602 
Sua classificação toxicológica é de nível III (Medianamente Tóxico) e sua classificação ambiental é do tipo III (Produto Perigoso) (BASF, 2011).

De acordo com a Ficha de Informação de Segurança de Produtos Químicos (FISQP) informada pelo fabricante, este produto é altamente persistente no meio ambiente e altamente móvel, apresentando alto potencial de deslocamento no solo, podendo atingir principalmente águas subterrâneas (BASF, 2011).

Um pesticida é capaz de contaminar os lençóis freáticos se a sua solubilidade em água for superior a $30 \mathrm{mg} \cdot \mathrm{L}^{-1}$; o seu coeficiente de partição do carbono orgânico $\left(\mathrm{K}_{\mathrm{OC}}\right)$, inferior a $300 \mathrm{~mL} \cdot \mathrm{g}^{-1}$; a constante de distribuição de adsorção $\left(\mathrm{K}_{\mathrm{d}}\right)$, inferior a $5 \mathrm{~mL} \cdot \mathrm{g}^{-1}$ e seu tempo de meia-vida, maior do que três semanas (BRASIL, 2004), sendo que para o BS os índices de solubilidade em água é $570 \mathrm{mg} \cdot \mathrm{L}^{-1}, \mathrm{t}_{1 / 2 \text { solo }}>940 \mathrm{~h}, \mathrm{t}_{1 / 2 \text { água }}=65-96 \mathrm{~h}$ (EYHERAGUIBEL et al., 2009), e o $\mathrm{K}_{\mathrm{OC}}=34 \mathrm{mLg}^{-1}$ (PRIMEL et al., 2005).

No Brasil, o Ministério da Saúde estabelece que o Valor Máximo Permitido (VMP) para a bentazona é de $300 \mu \mathrm{g} . \mathrm{L}^{-1}$ para águas destinadas ao consumo humano (SEAB-PR, 1997).

O principal problema da utilização de defensivos agrícolas em larga escala são a contaminação ambiental e o surgimento de espécies resistentes (VARGAS et al., 2007; DAN et al., 2013).

Apesar de ainda pouco utilizado no Brasil, o BS é largamente utilizado no continente europeu. Estudos realizados mostram a disseminação e a persistência da bentazona em águas naturais.

Loos et al. (2010), em um estudo que abrangeu 164 localizações englobando 23 países europeus, detectaram a presença de bentazona em lençóis freáticos na concentração de $11 \mu \mathrm{g} . \mathrm{L}^{-1}$. Malaguerra et al. (2012) investigaram a contaminação por pesticidas em poços artesianos na cidade de Zealand, na Dinamarca. Os resultados mostraram que os poços localizados na área não urbana estavam contaminados com bentazona, devido a sua larga utilização na agricultura dinamarquesa.

Kuster et al. (2008) detectaram a presença de bentazona em níveis médios de 30,51 $\mu \mathrm{g} . \mathrm{L}^{-1}$ e máximo de $126,8 \mu \mathrm{g} . \mathrm{L}^{-1}$, no delta do rio Ebro, uma conhecida região espanhola de cultivo de arroz.

Uma situação um pouco mais preocupante ocorre quando estes contaminantes são observados em água para consumo humano.

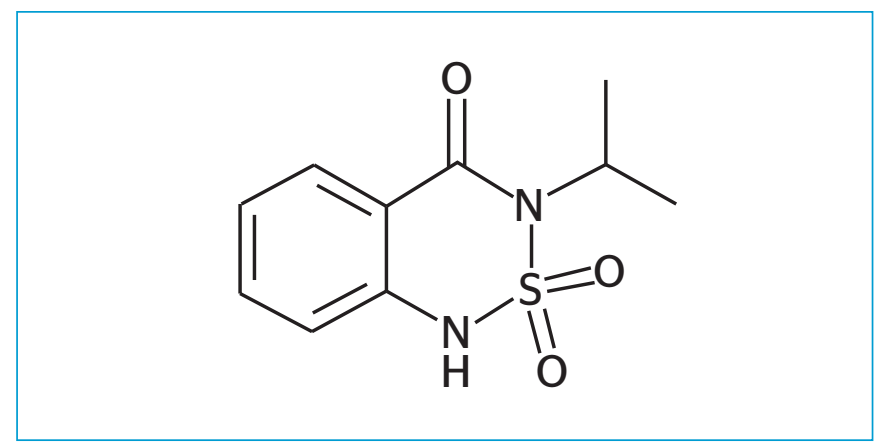

Figura 1 - Fórmula estrutural da bentazona (3-isopropil-1H-2,1,3-benzotiadiazin-4(3H)-ona-2,2-dióxido) ingrediente ativo do Basagran ${ }^{\circledast}$.
Gonzalez et al. (2008) verificaram que a bentazona foi refratária aos tratamentos microbiológicos (lodo ativado e biorreatores de membrana) geralmente empregados em Estações de Tratamento de Esgotos (ETE).

Para estes casos, onde se tem a ineficiência dos tratamentos biológicos ou físico-químicos, os Processos Oxidativos Avançados (POA) se apresentam como uma alternativa eficaz para a degradação de efluentes gerados pela ação de herbicidas.

Os POA são caracterizados por transformar a grande maioria dos contaminantes orgânicos em espécies inócuas como dióxido de carbono, água e ânions inorgânicos (NOGUEIRA et al., 2007), através de reações de oxidação química intermediadas pelo radical hidroxila $\left(\mathrm{OH}^{-}\right)$, espécie extremamente reativa e pouco seletiva (JARDIM \& TEIXEIRA, 2008). Devido o seu alto potencial de oxidação ( $\left.\mathrm{E}^{\circ} 2,370 \mathrm{~V}\right)$ este radical é capaz de oxidar uma ampla variedade de compostos orgânicos (SANTANA et al., 2003).

Os radicais hidroxila podem ser gerados através de reações envolvendo oxidantes fortes, como ozônio $\left(\mathrm{O}_{3}\right)$ e peróxido de hidrogênio $\left(\mathrm{H}_{2} \mathrm{O}_{2}\right)$, sendo que a eficiência pode ser aumentada pela combinação com irradiação ultravioleta (UV) ou visível ou ainda catalisadores (íons metálicos, semicondutores).

Dentre os óxidos metálicos semicondutores mais conhecidos o $\mathrm{TiO}_{2}$ é o mais frequentemente utilizado, por ser considerado bastante ativo na fotocatálise de degradação de substâncias orgânicas, na forma de suspensões aquosas (TIBURTIUS et al., 2004) e por apresentar baixo custo.

A fotocatálise heterogênea envolve a presença de catalisadores semicondutores ativados por luz solar ou artificial (NOGUEIRA \& JARDIM, 1998). Irradiado com luz de comprimento de onda $(\lambda)$ inferior a $390 \mathrm{~nm}$, o semicondutor absorve fótons e os elétrons são promovidos da banda de valência para a banda de condução do semicondutor formando um par elétron/lacuna (Equação 1):

$\mathrm{TiO}_{2}+h(<390 \mathrm{~nm}) \rightarrow \mathrm{TiO}_{2}\left(\mathrm{e}_{\mathrm{CB}}{ }^{-}+\mathrm{h}_{\mathrm{VB}}{ }^{+}\right)$

O potencial da lacuna na banda de valência $\left(\mathrm{h}_{\mathrm{VB}}{ }^{+}\right)$é o suficiente positivo para gerar radicais hidroxila na superfície e o potencial do elétron na banda de condução $\left(\mathrm{e}_{\mathrm{CB}}{ }^{-}\right)$é negativo o suficiente para reduzir o oxigênio molecular (POURATA et al., 2009).

Adicionalmente, os elétrons da banda de condução reduzem o $\mathrm{O}_{2}$ adsorvido formando o radical superóxido (Equação 2), o qual pode reagir com diversas espécies ou gerar radicais hidroxila (Equação 3):

$$
\begin{aligned}
& \mathrm{e}_{\mathrm{CB}-}+\mathrm{O}_{2(\mathrm{ads})} \rightarrow \mathrm{O}_{2(\text { ads })}^{-\cdot} \\
& \mathrm{O}_{2}^{-\cdot}+\mathrm{H}^{+} \rightarrow \mathrm{HO}_{2} \cdot
\end{aligned}
$$

O radical hidroxila gerado pela presença do catalisador é um poderoso agente oxidante, que ataca os poluentes orgânicos presentes ou nas proximidades da superfície do $\mathrm{TiO}_{2}$ (POURATA et al., 2009). 
O mecanismo de oxidação indireta dos contaminantes predomina sobre o direto devido à alta concentração de moléculas de água adsorvidas na superfície do semicondutor (MELO et al., 2009).

A oxidação de compostos orgânicos pelo radical hidroxila ocorre segundo três mecanismos básicos: abstração de prótons, transferência de elétrons e adição radicalar (ZIOLLI \& JARDIM, 1998). A predominância de uma ou de outra reação dependerá de vários fatores, entre eles a presença e concentração do substrato orgânico, bem como de sua recalcitrância (SANTANA et al., 2003).

O presente trabalho teve como objetivo verificar a viabilidade técnica da degradação fotocatalítica, utilizando o processo de fotocatálise UV/ $\mathrm{TiO}_{2}$ no tratamento de efluentes contendo bentazona. Neste trabalho, estudou-se a cinética da degradação fotocatalítica deste herbicida em solução aquosa, usando-se um reator do tipo slurry e $\mathrm{TiO}_{2}$ como catalisador.

\section{Parte experimental}

\section{Materiais e reagentes}

Os ensaios foram realizados em uma câmara de irradiação que consistia de uma caixa de madeira com dimensões, em centímetros, de $50 \times 40 \times 40$ $(\mathrm{L} \times \mathrm{A} \times \mathrm{P})$. Na parte superior, foi instalada uma lâmpada de vapor mercúrio de alta pressão de $125 \mathrm{~W}$ de potência $(G E)$, cujo bulbo externo foi retirado, de modo a se evitar o efeito filtro da luz UV exercido pelo vidro. Em seu interior foi colocado um agitador magnético sobre um lab-jack para a elevação da solução a ser fotolisada, como demonstrado na Figura 2. A distância entre a lâmpada e a superfície da solução era em torno de $11 \mathrm{~cm}$.

O monitoramento da temperatura foi feito usando-se um termômetro digital que foi imerso na solução após cada retirada de alíquota.

Como catalisador foi utilizado $\mathrm{TiO}_{2}(80 \%$ anatase- $20 \%$ rutilo, Aldrich), tamanho de partícula $<100 \mathrm{~nm}$ (BET 99,9\%), sem tratamento prévio, na concentração de 0,03 g.L $L^{-1}$.

A bentazona, produzida pela BASF, foi adquirida no comércio local na forma do defensivo agrícola Basagran ${ }^{\circledR} 600$, que consiste de uma solução contendo $600 \mathrm{~g}$ de bentazona por litro de solução.

\section{METODOLOGIA}

As soluções de análise foram preparadas a partir do produto comercial pela retirada de uma alíquota de $2 \mathrm{~mL}$ que foi avolumada à $100 \mathrm{~mL}$ em balão volumétrico, obtendo-se uma solução-mãe de concentração $5 \times 10^{-2}$ mol.L-1 . Desta solução foram retiradas alíquotas de $2,5 \mathrm{~mL}$ que foram diluídas a $250 \mathrm{~mL}$ em balão volumétrico, obtendo-se soluções de análise na concentração de $5 \times 10^{-4} \mathrm{~mol} \mathrm{~L}^{-1}$. Estas soluções foram transferidas para béqueres de capacidade adequada e irradiadas.

A solução foi mantida sob agitação na ausência de irradiação por 60 min, de modo a se atingir o equilíbrio de adsorção da bentazona na superfície do catalisador. A lâmpada era mantida acesa por 2 min antes de iniciar a reação, para se atingir o máximo de irradiação.

Durante os experimentos, alíquotas de 2,5 a $3 \mathrm{~mL}$ eram coletadas em intervalos regulares de $10 \mathrm{~min}$, utilizando-se uma seringa. As amostras foram filtradas numa unidade filtrante estéril e descartável (MILLEX poro $0,22 \mu \mathrm{m}$ ) para garantir a máxima remoção possível do dióxido de titânio, evitando-se assim espalhamento da luz no espectrofotômetro. Em todos os ensaios a variação máxima do volume foi de $30 \mathrm{~mL}$.

$\mathrm{O} \mathrm{pH}$ da mistura reacional era monitorado em três etapas distintas: na solução de bentazona antes de adicionar o catalisador, na mistura reacional após a adição de catalisador e ao final da reação.

Após as filtragens, a amostra era analisada em um espectrofotômetro Shimadzu UV modelo 1601PC UV. Todos os experimentos foram realizados, no mínimo, em duplicata.

\section{RESULTADOS E DISCUSSÕES}

\section{Aplicação direta de fotólise}

O processo de fotólise direta se deu mediante a incidência unicamente de radiação ultravioleta. Partindo-se de $250 \mathrm{~mL}$ de solução com concentração $5 \times 10^{-4} \mathrm{~mol} . \mathrm{L}^{-1}$, fez-se a incidência direta de luz por $90 \mathrm{~min}$. Foram coletadas duas alíquotas, uma no início sem haver irradiação e a segunda após a irradiação.

Juntamente a este estudo, tendo a mesma quantidade de solução de mesma concentração, investigou-se a reação fotocatalítica.

A Figura 3 apresenta os espectros de absorção na faixa do UV-Vis dos experimentos antes e após a fotólise direta, bem como da fotocatálise, em relação ao tempo.

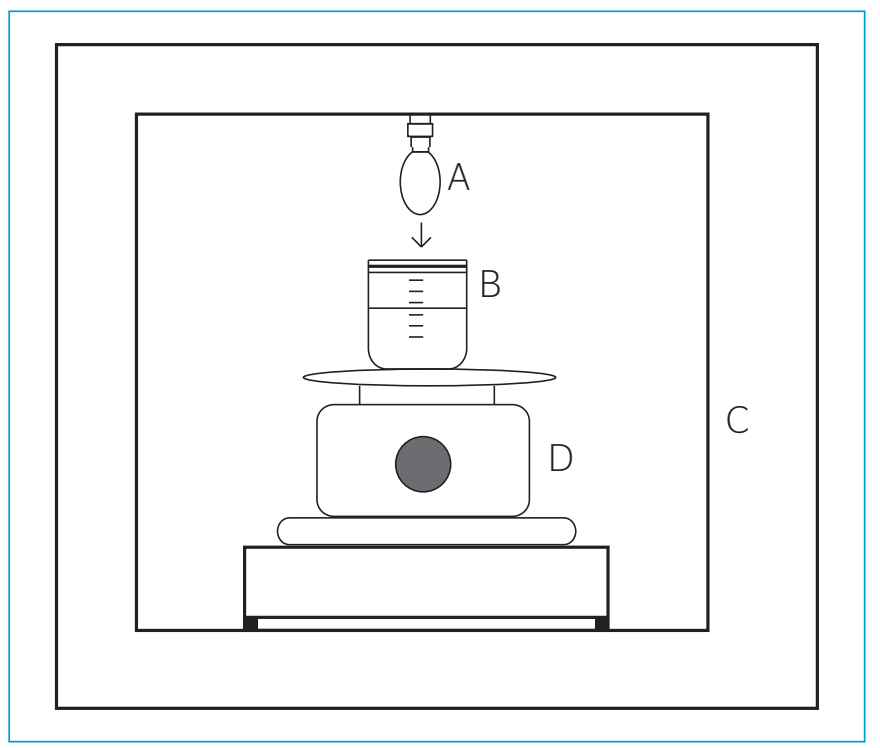

Figura 2 - Esquema experimental utilizado na fotodegradação de pesticida. (A) lâmpada de Hg; (B) béquer; (C) caixa de MDF; (D) agitador magnético; (E) lab-jack. 
Observando os espectros, verifica-se que a técnica de irradiação direta acarreta mínima redução dos valores de absorvância em comprimentos de onda em torno de $335 \mathrm{~nm}$, bem como a $225 \mathrm{~nm}$, tornando-se praticamente desprezível quanto à finalidade de degradação do efluente contendo pesticida bentazona.

Em relação ao processo de fotocatálise, houve uma degradação eficiente, comprovando que adição de agente oxidante acarreta um decréscimo maior dos valores de absorvância em relação ao tratamento de fotólise direta. Assim, tem-se um indicativo do efeito cooperativo da radiação e do agente oxidante.

\section{Aplicação do processo conjugado $\left(\mathrm{UV} / \mathrm{TiO}_{2}\right) \backslash$}

De modo similar aos ensaios anteriores, procedeu-se a incidência de radiação ultravioleta, porém na presença do oxidante $\mathrm{TiO}_{2}$.

Durante a realização dos experimentos de $\mathrm{UV} / \mathrm{TiO}_{2}$ coletaram-se alíquotas da mistura reacional que foram submetidas a análise de $\mathrm{pH}$ e temperatura. Observou-se um aumento na temperatura, provavelmente devido à incidência da radiação pelo fato do reator não possuir um sistema de resfriamento, e a diminuição do pH do meio.

A Figura 4 mostra o comportamento do espectro de absorção em função do tempo de irradiação. Em função dos valores de absorvância para a banda localizada em $335 \mathrm{~nm}$ nos diferentes tempos de irradiação foram calculadas as taxas de percentuais de degradação do herbicida em função do tempo de irradiação. Assim, para 20 min de irradiação foi calculada uma remoção de $10 \%, 50 \%$ para $80 \mathrm{~min}, 85 \%$ para 180 min e $100 \%$ para $270 \mathrm{~min}$. Os mesmos cálculos foram efetuados para a banda centrada em $225 \mathrm{~nm}$, obtendo-se uma taxa de degradação de 20\% para o tempo de irradiação de 20 min e $60 \%$ para 80 min.

Estes experimentos indicam que tanto a luz quanto o fotocatalisador $\mathrm{TiO}_{2}$ são necessários para a degradação efetiva da bentazona.

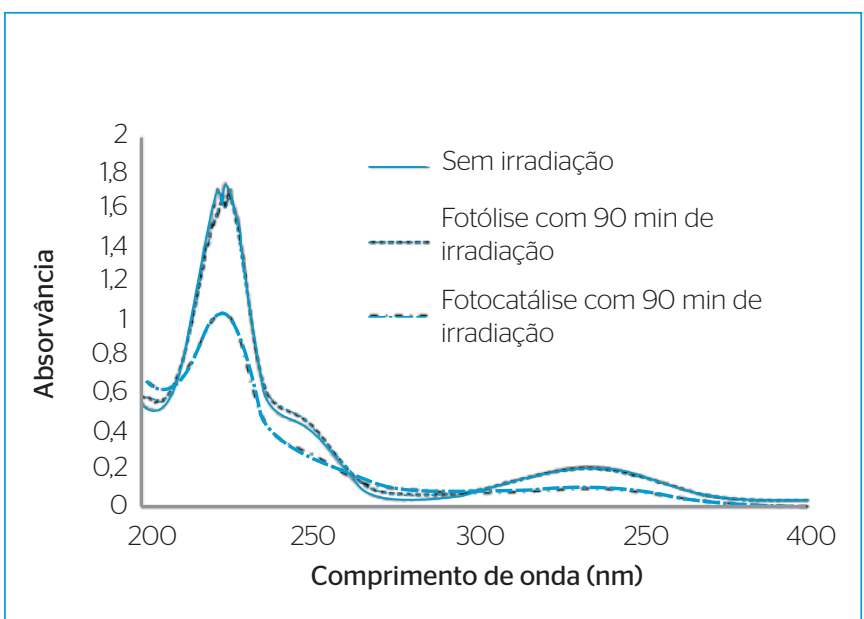

Figura 3 - Espectros de absorvância das soluções contendo [bentazo$\mathrm{nal}_{0}=5 \times 10^{-4}$ mol. $\mathrm{L}^{-1}$ pelos processos de fotólise e fotocatálise.
Muitos estudos com $\mathrm{TiO}_{2}$ têm sido desenvolvidos, mas seu mecanismo de reação ainda não é totalmente compreendido. Acredita-se que o $\mathrm{O}_{2}$ é a principal espécie responsável em dar continuidade às reações iniciadas no processo de foto-oxidação, reagindo com o radical orgânico formado e levando-o à completa mineralização (FREIRE et al., 2000).

A maioria dos poluentes orgânicos aromáticos e alifáticos é totalmente mineralizado em $\mathrm{CO}_{2}$ e ânions inorgânicos. Moléculas complexas como pesticidas (herbicidas, inseticidas, fungicidas, etc.) são totalmente destruídas. Isto resulta do ataque por radicais $\mathrm{OH}$, conhecido como o segundo oxidante mais forte (HERRMAN et al., 2007).

\section{Avaliação cinética}

Para a avaliação cinética da degradação da bentazona em suspensão aquosa de $\mathrm{TiO}_{2}$, foi considerado um processo de pseudo-primeira ordem. Neste caso, o tratamento matemático relaciona a variação da concentração da bentazona em função do tempo de irradiação (Equação 4). Integrando-se no intervalo de tempo $t=0$ e $t$, e que para $t=0$, [bentazona $]=[\text { bentazona }]_{0}$ chega-se a relação descrita na Equação 5.

$$
\left.-\frac{\mathrm{d}[\text { bentazonal }]}{\mathrm{dt}}=\mathrm{k}_{\mathrm{obs}} \text { [bentazona }\right]
$$

$\ln \left(\frac{[\text { bentazonal }]_{0}}{[\text { bentazonal }]}\right)=\mathrm{k}_{\mathrm{obs}} \times \mathrm{t}$

Traçando-se o gráfico de $\ln \left(\mathrm{C}_{0} / \mathrm{C}\right)$ versus tempo e ajustando os dados experimentais se observa um comportamento linear dos pontos experimentais $\left(\mathrm{R}^{2}=0,99\right.$ - Figura 5$)$. Desta forma, conclui-se que a fotocatálise seguiu uma cinética de pseudo-primeira ordem, e a constante

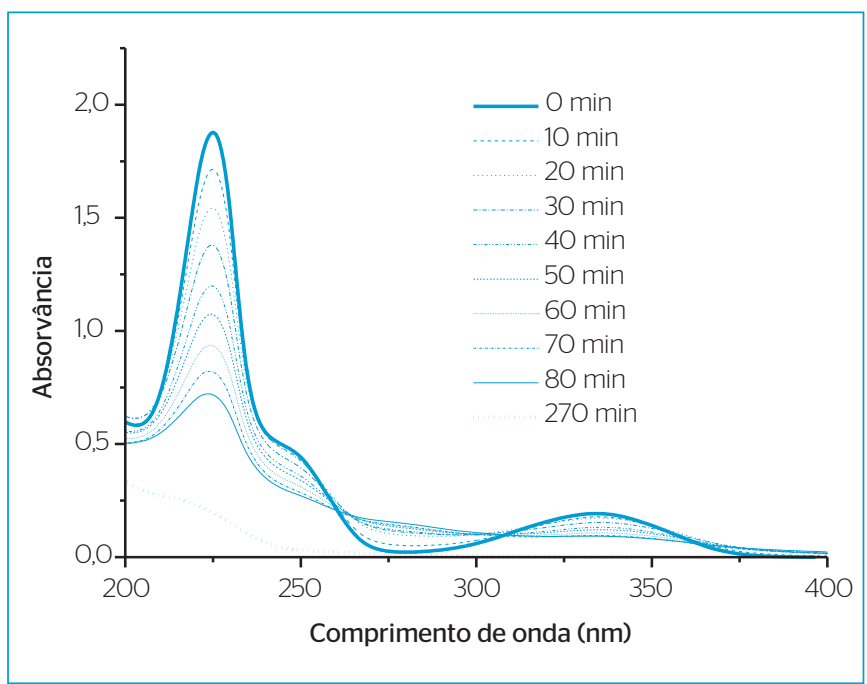

Figura 4 - Espectro de absorvância das soluções de efluente de bentazona durante a aplicação do processo de $\mathrm{UV} / \mathrm{TiO}_{2}$ no reator

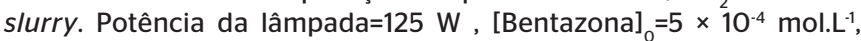
$\left[\mathrm{TiO}_{2}\right]=0,030 \mathrm{~g} \cdot \mathrm{L}^{-1}$. 
de velocidade do processo, estimada pelo coeficiente angular da reta, foi de $\mathrm{k}=0,0116 \mathrm{~min}^{-1}$.

\section{Efeito da concentração inicial do catalisador e de bentazona}

Primeiramente utilizou-se uma solução cuja concentração da bentazona estava em excesso em relação ao $\mathrm{TiO}_{2}$. Os ensaios não demonstraram diferença nos espectros de quanto a degradação, em qualquer tempo de irradiação. Provavelmente isto ocorreu devido uma alta quantidade de moléculas adsorvidas na superfície do $\mathrm{TiO}_{2}$ impedindo assim a passagem de luz UV, não fotogerando radicais hidroxila bem como pares elétron/lacuna.

Uma vez que a concentração do herbicida é muito alta, também faz com que as moléculas do herbicida absorvam fótons de luz e estes nunca atinjam a superfície do catalisador, portanto, diminuindo a remoção fotocatalítica (POURATA et al., 2009).

Em outro estudo, a concentração do catalisador foi muito maior do que a concentração inicial da bentazona, mas, mais uma vez, os ensaios não apresentaram nenhum resultado. Provavelmente devido à alta quantidade de moléculas de $\mathrm{TiO}_{2}$ em suspensão no meio reacional causando opacidade, diminuindo a penetração da luz através da solução e, ainda, causando espalhamento de luz. Assim, nem todas as partículas receberam energia suficiente para promover o elétron da banda de valência para a banda de condução, e, assim, iniciar a oxidação da bentazona.

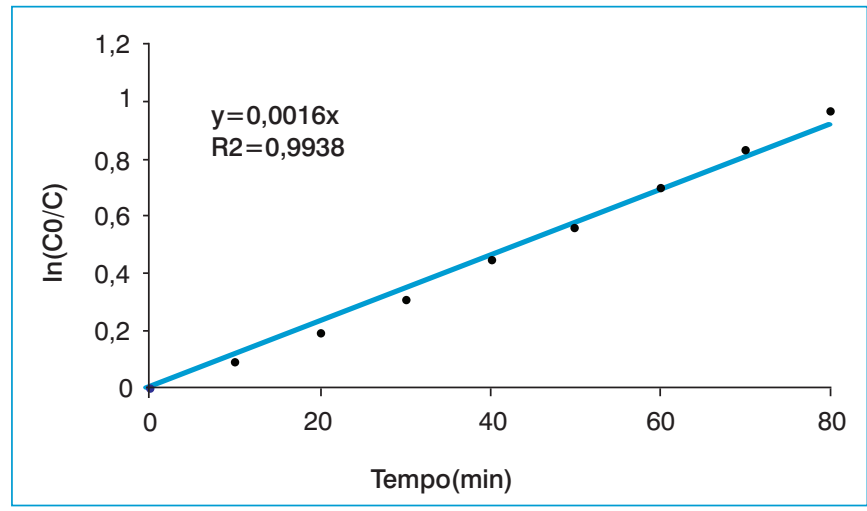

Figura 5 - Reação de degradação da bentazona. Potência da lâmpada $\mathrm{Hg}: 125 \mathrm{~W}$. $\left[\mathrm{TiO}_{2}\right]=0,03 \mathrm{~g} \cdot \mathrm{L}^{-1}$ e $\mathrm{C}_{0}=5 \times 10^{-4} \mathrm{~mol}^{\mathrm{L} \mathrm{L}^{-1}}$.

\section{CONCLUSÕES}

Os resultados obtidos neste trabalho permitiram concluir que o método empregado para a degradação do herbicida bentazona em solução aquosa, com a utilização de $\mathrm{TiO}_{2}$ em suspensão e irradiação ultravioleta mostrou-se eficiente. A degradação obedeceu a uma cinética de pseudo-primeira ordem com $\mathrm{k}=0,0116 \mathrm{~min}^{-1}$.

Observou-se também que a degradação da bentazona por fotólise é mínima, mesmo após 270 min de irradiação. Por outro lado, o processo fotocatalítico atingiu $100 \%$ de degradação após o mesmo período de tempo.

Contudo, maiores estudos devem ser realizados, principalmente em relação à caracterização dos produtos finais da reação.

\section{REFERÊNCIAS}

ABRASCO. (2012) Um alerta sobre os impactos dos agrotóxicos na saúde. Disponível em: <http://www.abrasco.org.br/UserFiles/File/ ABRASCODIVULGA/2012/DossieAGT.pdf>. Acesso em 17 jul. 2013.

BASF, FISQP do Basagran ${ }^{\circledR}$. (2011) Disponível em: <http://www.agro. basf.com.br/agr/ms/apbrazil/pt_BR/function/conversions:/publish/ content/APBrazil/solutions/herbicides/FISPQ/BASAGRAN600.PDF>. Acesso em 17 jul 2013.

DAN, H.A.; BRAZ, G.B.P.; BIFFE, D.F.; ALONSO, D.G.; RAIMONDI, M.A. Histórico da Infestação de buva resistente a herbicidas no mundo e no Brasil. Disponível em: <http://omnipax.com.br/livros/2013/BFRM/bfrmcap02.pdf > . Acesso em 13 jul 2013.

EYHERAGUIBEL, B.; HALLE, A.T.; RICHARD, C. (2009) Photodegradation of bentazon, clopyralid and triclopyr on model leaves: Importance of a systematic evaluation of pesticide photostability on crops. Journal of Agricultural and Food Chemistry, v. 57, n. 5, p. 1960-1966.
FREIRE, R.S.; PELEGRINI, R., KUBOTA, L.T.; DURÁN, N. (2000) Novas tendências para o tratamento de resíduos industriais contendo espécies organocloradas. Química Nova, v. 23, n. 4, p. 504-511.

GONZÁLEZ, S.; MÜLLER, J.; PETROVIC, M.; BARCELÓ, D.; KNEPPER, T.P. (2006) Biodegradation studies of selected priority acidic pesticides and diclofenac in different bioreactors. Environmental Pollution, v. 144, n. 3, p. 926-932.

HERRMANN, J.M.; DUCHAMP, C.; KARKMAZ, M.; HOAI, B.T.; LACHHEB, H.; PUZENAT, E.; GUILLARD, C. (2007) Environmental green chemistry as defined by photocatalysis. Journal of Hazardous Materials, v. 146, n. 3, p. 624-629.

BRASIL (2013). Instituto Brasileiro de Geografia e Estatísticas IBGE. Disponível em: <http://www.ibge.gov.br/home/estatistica/ indicadores/agropecuaria/Ispa/Ispa_201303comentarios.pdf $>$. Acesso em 17 jul 2013. 
JARDIM, W.F. \& TEIXEIRA, C.P.A.B. Processos oxidativos avançados. Caderno Temático, v. 3. Disponível em: <http://lqa.iqm.unicamp.br/>. Acesso em 17 jul 2013.

KUSTER, M.; LÓPES DE ALDA, M.J.; BARATA, C.; RALDÚA, D.; BARCELÓ, D. (2008) Analysis of 17 polar to semi-polar pesticides in the Ebro river delta during the main growing season of rice by automated on-line solid-phase extraction-liquid chromatography-tandem mass spectrometry. Talanta, v. 75, n. 2, p. 390-401.

LOOS, R.; LOCORO, G.; COMERO, S.; CONTINI, S.; SCHWESIG, D.; WERRES, F.; BALSAA, P.; GANS, O.; WEISS, S.; BLAHA, L.; BOLCHI, M.; GAWLIK, B.M. (2010) Pan-European survey on the occurrence of selected polar organic persistent pollutants in ground water. Water Research, v. 44, n. 14, p. 4115-4126.

MALAGUERRA, F.; ALBRECHTSEN, H.J.; THORLING, L.; BINNING, P.J. (2012) Pesticides in water supply wells in Zealand, Denmark: A statistical analysis. Science of Total Environment, v. 414, p. 433-444.

MELO, S.A.; TROVÓ, A.G.; BAUTITZ, I.R.; NOGUEIRA, R.F.P. (2009) Degradação de fármacos residuais por processos oxidativos avançados. Química Nova, v. 32, n. 1, p. 188-197.

BRASIL. (2004) Ministério da Saúde, Portaria n 518/2004, 25 de março de 2004. Diário Oficial da União, Brasília, 2004. Disponível em: <http:// portal.saude.gov.br/portal/arquivos/pdf/portaria_518_2004.pdf > . Acesso em 13 jul. 2010

NOGUEIRA, R.F.P. \& JARDIM,W.F. (1998) A fotocatálise heterogênea e sua aplicação ambiental. Química Nova, v. 21, n. 1, p. 69-72.

NOGUEIRA, R.F.P.; TROVÓ, A.G.; SILVA, M.R.A.; VILLA, R.D. (2007) Fundaments and environmental applications of Fenton and photoFenton processes. Química Nova, v. 30, n. 2, p. 400-408.

PORTAL TERRA (2011). ONU divulga projeção sobre população mundial. Disponível em: <http://noticias.terra.com.br/mundo/onu- divulga-projecao-sobre-populacao-mundial-veja-numeros,ce08df4cd8 5ea310VgnCLD200000bbcceb0aRCRD.html>. Acesso em 17 jul 2013.

POURATA, R.; KHATAEE, A.R.; ABER, S.; DANESHVAR, N. (2009) Removal of the herbicide Bentazon from contaminated water in the presence of synthesized nanocrystalline $\mathrm{TiO}_{2}$ powders under of UV-C radiation. Desalination, v. 249, n. 1, p. 301-307.

PRIMEL, E.G.; ZANELLA, R.; KURZ, M.H.S.; GONÇALVES, F.F.; MACHADO, S.O.; MARCHEZAN, E. (2005) Poluição das águas por herbicidas utilizados no cultivo do arroz irrigado na região central do estado do Rio Grande do Sul, Brasil: predição teórica e monitoramento. Química Nova, v. 28, n. 4, p. 605-609.

SANTANA, H.; BONANCÊA, C.E.; TAKASHIMA, K. (2003) Fotocatálise eletroquímica de atrazina sobre dióxido de titânio: efeito de diferentes parâmetros experimentais. Química Nova, v. 26, n. 6, p. 807-811.

GOVERNO DO ESTADO DO PARANÁ. Secretaria da Agricultura e do Abastecimento. (1997) Coletânea da Legislação Estadual e Federal de Agrotóxicos. Curitiba: SEAB/DEFIS.

TIBURTIUS, E.R.L.; PERALTA-ZAMORA, P.; LEAL, E.S. (2004) Contaminação de águas por BTXs e processos utilizados na remediação de sítios contaminados. Química Nova, v. 27, n. 3, p. 441-446.

BRUXELAS. (2011) Centro Regional de Informação das Nações Unidas UNRIC. População mundial excederá 9 mil milhões em 2050, segundo ONU. Disponível em: <http://www.unric.org/pt/envelhecimento/22724>. Acesso em 17 jul 2013.

VARGAS, L.; BIANCHI, M.A.; RIZZARDI, M.A.; AGOSTINETTO, D.; DAL MAGRO, T. (2007) Buva (Conyza bonariensis) resistente ao glyphosate na região sul do Brasil. Planta Daninha, v. 25, n. 3, p. 573-578.

ZIOLLI, R.L. \& JARDIM, W.F. (1998) Mecanismo de fotodegradação de compostos orgânicos catalisada por $\mathrm{TiO}_{2}$. Química Nova, v. 21, n. 3, p. 319-325. 